\title{
La educación especial en tiempos de la COVID-19
}



\section{Sostener el aprendizaje de un hijjo con discapacidad intelectual durante el confinamiento}

El papel de la familia es clave en la superación de las dificultades especiales que pueden tener los niños con discapacidad intelectual para beneficiarse de la educación a distancia. Este artículo ofrece diez consejos para las familias, nacidos de la experiencia

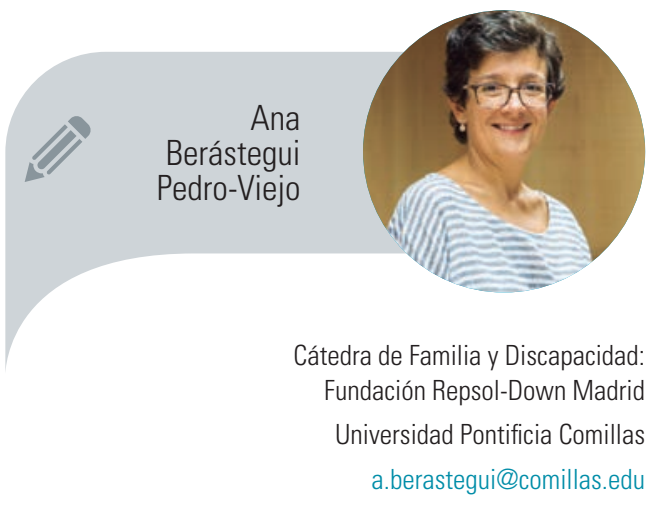
personal de la autora, y también algunos aprendizajes que pueden ser útiles de cara al futuro. 

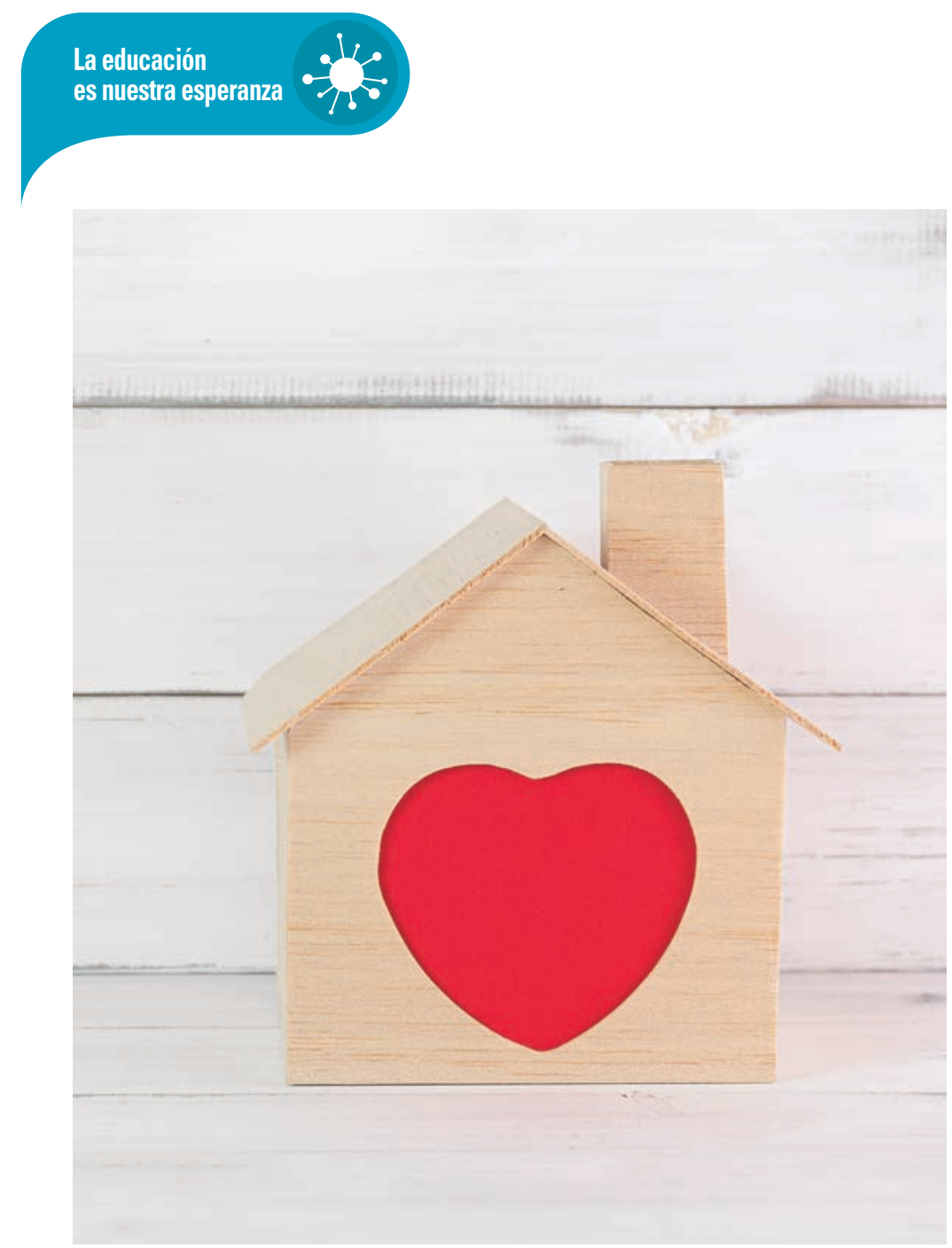

El alumnado con discapacidad intelectual o del desarrollo se ha convertido en un grupo especialmente vulnerable por el cierre de los colegios, tal y como denuncia la Federación de Asociaciones Plena Inclusión. Estos alumnos encuentran especiales dificultades para seguir desde sus hogares los contenidos que se facilitan a través de internet por varias razones: la brecha digital afecta en mayor medida a las familias en las que hay niños con discapacidad, se acusan las dificultades de acceso y adaptación de los materiales, las barreras a la comunicación se multiplican en los contextos digitales, pero sobre todo, se evidencia la necesidad de apoyos personalizados y presenciales para el mantenimiento de la atención, la organización del tiempo y el desarrollo de las tareas.

Las familias, en medio de los problemas de salud, los temores por la situación, la ruptura de las rutinas familiares y las tensiones de la conciliación de la vida familiar y laboral, somos el único puente disponible para superar esa brecha, que puede hacer crecer las desigualdades educativas para nuestros hijos por culpa de esta situación. Este artículo pretende, a modo de decálogo, ofrecer mi experiencia después de un mes sosteniendo la "escolarización en casa" de un niño de 12 años con síndrome de Down, que cursa segundo ciclo de EBO en un colegio de educación especial. Por supuesto, estas diez palabras no pretenden ser mandamientos: mi experiencia no es necesariamente similar, ni mejor, a la experiencia de otras familias que tienen hijos con síndrome de Down o hijos con discapacidad o hijos de 12 años, porque lo primero que nos caracteriza como colectivo es la enorme variabilidad de puntos de partida personales, familiares y contextuales. Estas diez palabras pretenden ser aprendizajes, automensajes, palabras guía para estos días y también para el día después. Pretenden ser también puntos de encuentro que nos ayuden a reflexionar sobre las necesidades educativas de estos niños y el papel de la familia en su consecución.

1. Ofrece seguridad. Estos son tiempos de inseguridad para todos: inseguridad en el ambiente, inseguridad en los adultos transmitida a los niños, inseguridad por la ruptura de la cotidianeidad que hace el mundo comprensible. Ningún niño puede aprender si se siente inseguro, por lo que debemos priorizar todo lo que nos ayude a conseguir una cierta sensación de seguridad en casa, que nos permita empezar a trabajar. La sensación de inseguridad afectiva, la imposibilidad de moverse con cierta autonomía o de encontrar consuelo y comprensión frente al malestar suele manifestarse, cuando el lenguaje no es muy eficaz, en forma de problemas de conducta, con lo que la inseguridad puede convertirse en el inicio de un círculo vicioso de malestar para todos. Así que lo primero de todo, antes y por encima de cualquier tarea u objetivo educativo, es escuchar estas necesidades afectivas de exploración, de consuelo, de comprensión, y tratar de responder de la mejor manera posible.

2. Crea rutinas (y aprende a saltártelas). Antes el día venía organizado desde 


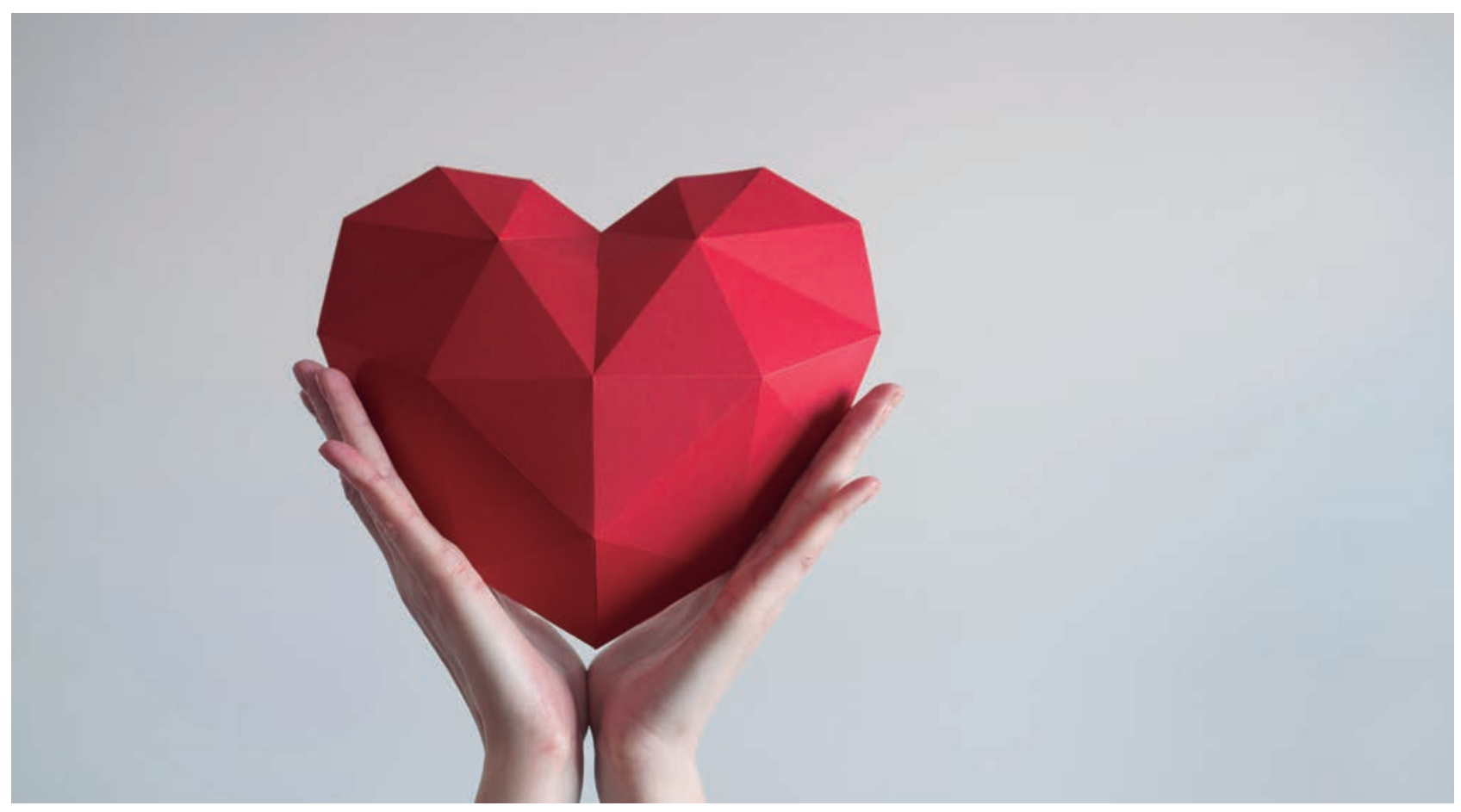

fuera, ahora tenemos que aprender a organizarlo y puede resultar difícil tomar decisiones sobre a qué dedicar el tiempo. Es el momento de crear nuevas rutinas y dar al niño un papel relevante en la toma de decisiones, fomentando su autodeterminación. En casa hemos dividido el día en 5 tiempos, separados por las principales comidas del día: del desayuno al almuerzo, a la comida, a la merienda y a la cena, y después de cenar, y cada uno de esos huecos tiene sus actividades. La actividad propiamente escolar se coloca en el hueco después de almorzar (clase) y después de merendar (deberes) y el niño tiene la posibilidad de elegir otras dos actividades para cada bloque de tiempo. Con respecto al trabajo "formal", como en el deporte, más vale un poquito cada día que intentar solucionar de un plumazo todo el trabajo de la semana. Con respecto al "tiempo libre", que se ha doblado, la tendencia del niño puede ser elegir siempre la misma actividad, por lo que habrá que ofrecer variedad de ellas para elegir, o "estirar" un poco la actividad elegida para que incluya alguna novedad o pueda apoyar algún aprendizaje. Siguiendo una planificación consensuada el día se hace más fácil para todos. Pero también hay que aprender a saltarse la planificación, o planificar algún día de

\section{Lo primero de todo, antes y por encima de cualquier tarea u objetivo educativo, es escuchar estas necesidades afectivas y tratar de responder de la mejor manera posible}

forma diferente; por ejemplo, los fines de semana, o si irrumpe algún acontecimiento inesperado.

3. Sitúate. Una de las cuestiones que más ayudan a construir la seguridad es poder situarnos en el tiempo, en el espacio, en el adentro, lo que nos ayuda a ganar cierta sensación de control. Por eso, antes de comenzar el trabajo formal contestamos algunas preguntas importantes, igual que se hace en el cole: ¿qué día es? ¿Qué tiempo hace? ¿Dónde estamos? ¿Cómo me siento? ¿Qué vamos a hacer en este rato? Para cada una de estas preguntas hemos creado un "comunicador" con pictogramas y velcro en el que podemos colocar pictogramas que contesten a estas preguntas. En el momento de "¿dónde estamos?" recordamos que en la calle hay coronavirus y por eso todos tenemos que estar 


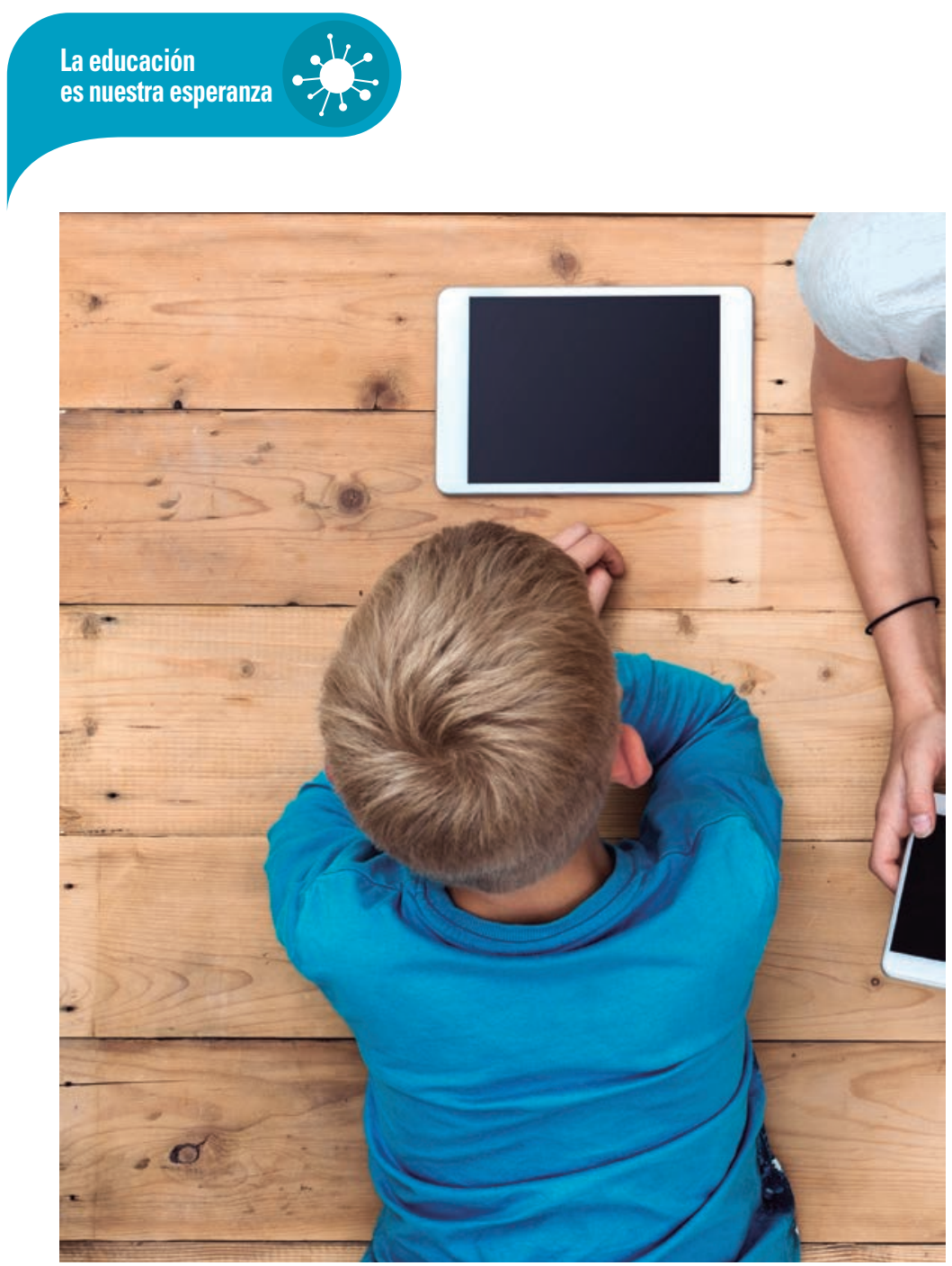

en casa, colocando en su casa a todos los amigos de clase y a la profe, a la familia completa dentro de la nuestra y el cole vacío. Nos ha parecido especialmente importante dedicar un momento para hablar de "¿cómo me siento?", antes de comenzar a trabajar, lo que nos permite también compartir y gestionar las emociones difíciles con respecto a esta situación.

4. Sostén la atención. De los aspectos más complicados en el apoyo del aprendizaje en casa, al menos en nuestro caso, es sostener la atención: la del niño y la del adulto. Con mi hijo, la idea de ofrecerle una tarea y dedicarme a hacer otras cosas mientras la desarrolla no es una opción. Es la atención del adulto en la tarea la que sostiene la suya, por lo que nuestra atención sobre la actividad tiene que ser plena para que él pueda atender. Por eso, igual que el niño necesita situarse, nosotros también necesitamos colocarnos en el aquí y ahora cuando trabajamos con él (nada de móviles, ordenadores, conversaciones, cocinar...). Desde mi punto de vista, la idea de mandar muchas tareas para que los niños estén entretenidos es contraproducente en estos casos, ya que solo podemos hacer el trabajo que desempeñamos adulto y niño compartiendo tiempo, espacio y atención. Además, hemos buscado un lugar de la casa en el que no haya interrupciones y si las hay, necesitamos ritualizar de alguna manera la vuelta a la atención (sentarnos bien, prepararnos, recordar lo que estábamos haciendo y qué nos falta, volver a comprender la consigna...).

5. No tengas prisa. En nuestro deseo de promover el desarrollo de nuestros hijos, las familias podemos llegar a tomarnos el aprendizaje como una carrera: ¿por qué letra va? ¿Cuántos números sabe? ¿A qué página del libro hemos llegado? Empeñarnos en comparar el rendimiento de nuestros hijos con sus compañeros a través de los grupos de familias no sirve de ayuda en este sentido. Una de las prácticas para que el aprendizaje sea profundo, significativo y útil es no tener prisa, no avanzar superficialmente. Algunos aprendizajes tardan en llegar, pero el que llega viene para quedarse, así que solo yendo despacito llegaremos todo lo lejos y todo lo hondo que permita nuestro hijo y nos mantendremos motivados y esperanzados por el camino.

6. Valora, sobre todo, los procesos. En parte relacionado con las prisas, podemos tratar de avanzar con rapidez en los contenidos, como si el aprendizaje fuera una cuestión puramente sumativa y acumulativa. En estos momentos de aprendizaje compartido, me estoy dando cuenta de la importancia clave que tienen las habilidades y los procesos básicos: sentarse bien ¿está preparado?, dirigir la atención ¿dónde está mirando?, comprender las tareas ¿qué tenemos que hacer?, autocontrolarse ¿qué está haciendo?, evaluar la ejecución ¿ha salido bien?, reparar ¿hay que borrar y hacer de nuevo? Hacer explícitos todos esos pasos permite descubrir dónde están las dificultades para el desempeño y dónde están 
los puntos fuertes del aprendizaje. Poner los procesos por delante, también nos permite aprovechar muchas situaciones informales de la vida cotidiana para aprender mates, lengua, ciencias, religión o psicomotricidad, además de autodeterminación, cuidado de la salud, habilidades sociales, herramientas de autonomía...

7. Menos es más. Esta atención a los procesos, a los pequeños componentes de la tarea, esta idea de avanzar sin prisas y sosteniendo la atención ha hecho que sea clave no dejarme seducir por la tormenta de recursos, tareas, retos, posibilidades e iniciativas que nos han bombardeado estos días. Necesitamos sentirnos seguros, entrar en rutina, situarnos, prestar atención, ir poquito a poco atendiendo a los procesos y eso es imposible si cada día probamos tres aplicaciones nuevas, vemos cinco videos por primera vez o pretendemos hacer diez manualidades divertidas. No es que no se puedan hacer cosas diferentes o innovadoras, es que hay que saber dosificar. En esto los profes nos pueden servir de filtro y también de organizador, seleccionando y planificando las actividades de la semana.

8. Mira y disfruta. Esta situación está suponiendo una oportunidad para ver de cerca cómo aprende nuestro hijo, lo que le interesa, lo que más le cuesta, para valorar el enorme esfuerzo y tesón con el que avanza y a sentirnos muy orgullosos de él. A veces me desespero, y me frustro y no puedo entender por qué después de tres "unos", de repente, escribe una "i" o un churro, pero entonces vuelvo a mirar y veo dónde hemos perdido el hilo, cuál es la dificultad y el milagro de todas las veces que funciona y disfruto enormemente de ver cómo mi hijo crece, a pasos quizás imperceptibles para otros, pero profundos y reales.

9. Mantente conectado. Uno de los grandes peligros de esta situación para los niños con discapacidad intelectual es aumentar el aislamiento social o perder algunas habilidades sociales

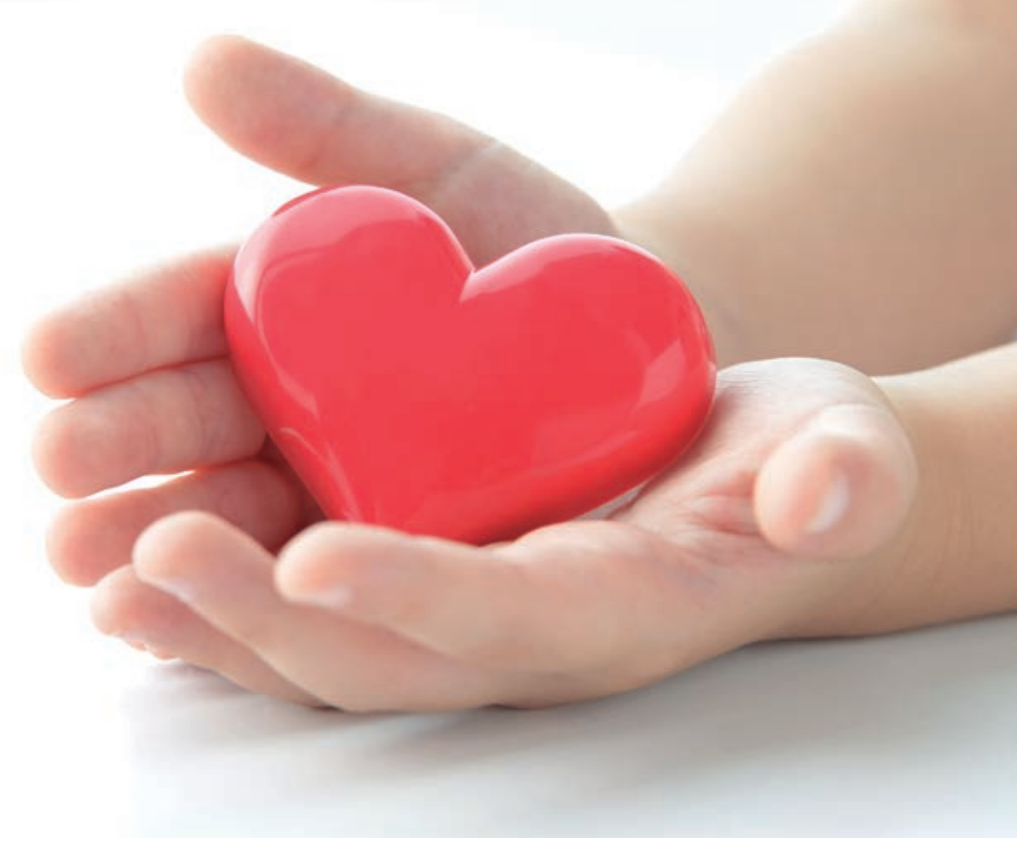

- que nos sintamos desbordados y solos frente a esta tarea y claudiquemos. Por eso es importante mantener abiertas las conexiones y el apoyo social, en la medida de lo posible, teniendo un contacto fluido y bidireccional con los profesores; no solo recibiendo instrucciones, sugerencias y tareas, sino también devolviéndoles cómo se está trabajando y lo que más ayuda o más difícil resulta. También mantener abierta la conexión entre el niño y sus profesores de referencia: a pesar de estar en familia la distancia de personas tan significativas como los profesores puede ser vivida como un duelo que puede aminorarse a través de la comunicación por audio y video, en directo y en diferido. Además, enseñar el trabajo realizado a los profesores puede ser una fuente de motivación para el aprendizaje. Por último, mantener la relación con los pares, que puede ser lo más difícil, porque puede exigir un grado de mediación adulta que limite la espontaneidad y el juego, pero que considero clave.

10. Sostén la esperanza pedagógica. Leo con inquietud estos días la preocupación de algunos familiares de niños con discapacidad intelectual que dicen que cada día en confinamiento, sin acceso a la escuela o al contacto con los profesionales especialistas (logo- 

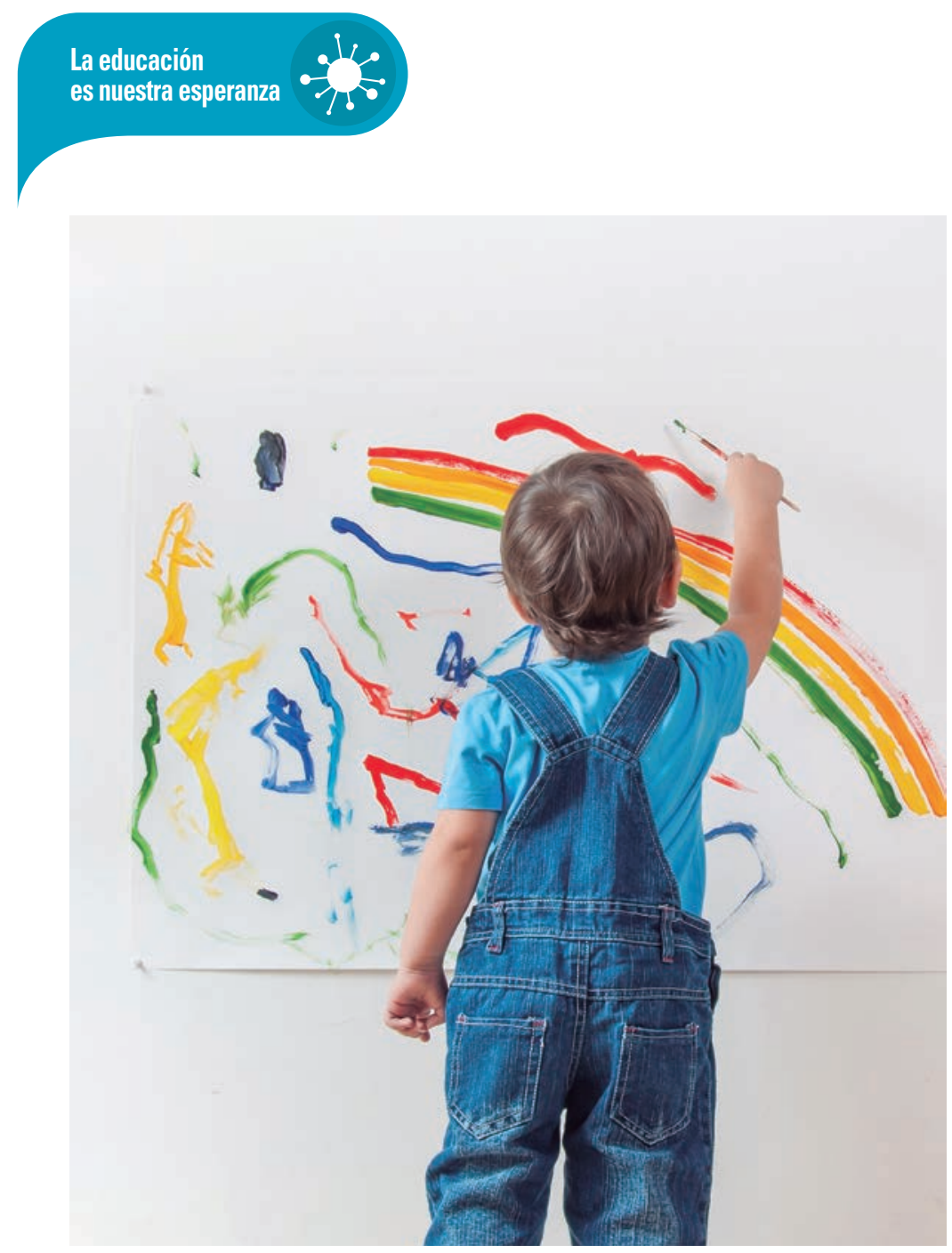

ha adquirido, iniciado o consolidado en este tiempo y también 5 cosas que nosotros mismos hemos aprendido sobre él o sobre nosotros como padres.

La esperanza pedagógica no nos impide reconocer que esta situación dista mucho de ser la ideal. Sin embargo, nos permite extraer algunos aprendizajes para "el día después" en la educación de los niños con discapacidad intelectual. Algunas de las cosas que he aprendido yo de este tiempo, y que son indudablemente más que cinco, son:

7 Que mi hijo necesita sentirse seguro, acompañado y en relación para aprender.

入 Que mi hijo aprende mejor cuando el trabajo es individualizado y el apoyo es personalizado y, aun así, que su avance es lento y desigual.

入 Que los profesionales que sostienen cada día su aprendizaje tienen una tarea apasionante pero muy compleja, que he aprendido a valorar más aún si cabe.

pedas, fisioterapeutas, profesionales de atención temprana) es un día perdido, una marcha atrás, una derrota en la lucha por reducir las barreras en la vida de nuestros hijos. Creo que esta preocupación, aunque legítima, impide ver, mirar y creer en la capacidad de aprendizaje de nuestros hijos, y en la importancia que tenemos las familias, a pesar de no tener conocimientos técnicos, como motor y sostén de estos aprendizajes. Seguro que, bien mirado, cada familia podemos descubrir al menos 5 aprendizajes que nuestro hijo

\section{(DA) DARA SABER MÁS}

Bermejo Boixareu, M. (2020). Rosa contra el virus: cuento para explicar el coronavirus. Madrid: Editorial Sentir. Recuperado de https:// bit.ly/3eizD2P

El coronavirus en pictogramas. Recuperado de https://bit.ly/2B3IRmv PLENA INCLUsión. (2020). El derecho a la educación durante la COVID-19. Recuperado de https://bit.ly/2zuMaBz

Plena InCLusión. (2020). Propuestas para ayudar a las familias en proceso de desescalada. Recuperado de https://bit.ly/3cYIRRA

$\boldsymbol{\lambda}$ Que necesita encontrarse con sus iguales y conectarse socialmente porque hay cosas que los adultos no le podemos enseñar.

$\boldsymbol{\lambda}$ Que me encanta que mi hijo vaya al colegio y que me encanta el colegio de mi hijo. Sea en educación ordinaria con los apoyos necesarios, sea en educación especial, la escolarización de los niños con discapacidad es clave para asegurar su calidad de vida y su inclusión social •

HEMOS HABLADO DE

\section{Discapacidad intelectual; familia; enseñanza a distancia; COVID-19.}

Este artículo fue solicitado por PADRES Y MAESTROS en marzo de 2020, revisado y aceptado en mayo de 2020. 